This item was submitted to Loughborough's Research Repository by the author.

Items in Figshare are protected by copyright, with all rights reserved, unless otherwise indicated.

\title{
An investigation of the factors affecting the successful treatment of organisational issues in systems development projects
}

PLEASE CITE THE PUBLISHED VERSION

http://dx.doi.org/10.1057/palgrave.ejis.3000401

\section{PUBLISHER}

Palgrave Macmillan (@ Operational Research Society)

VERSION

AM (Accepted Manuscript)

\section{LICENCE}

CC BY-NC-ND 4.0

\section{REPOSITORY RECORD}

Doherty, Neil, and Malcolm King. 2019. "An Investigation of the Factors Affecting the Successful Treatment of Organisational Issues in Systems Development Projects”. figshare. https://hdl.handle.net/2134/8186. 
This item was submitted to Loughborough's Institutional Repository (https://dspace.lboro.ac.uk/) by the author and is made available under the following Creative Commons Licence conditions.

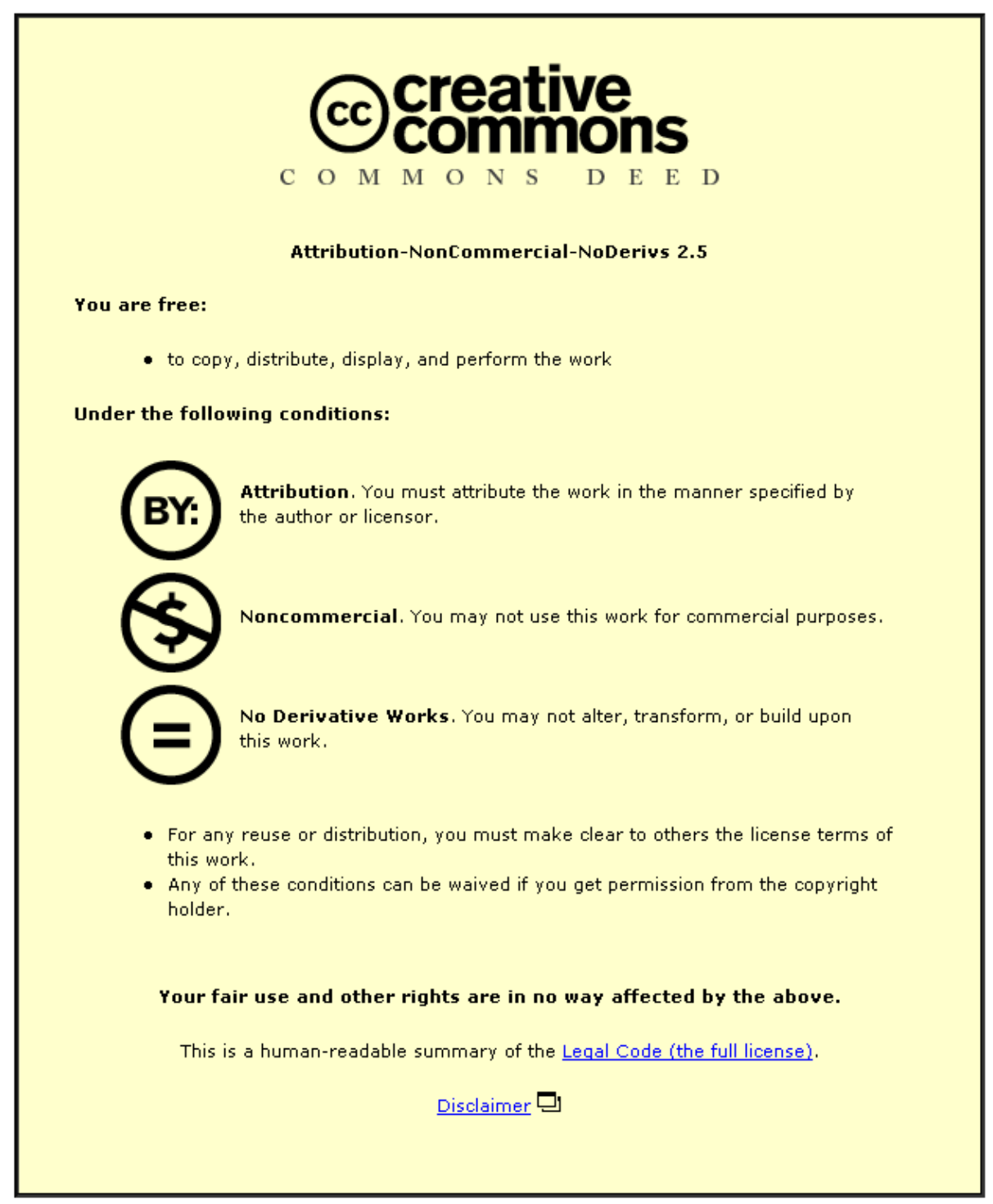

For the full text of this licence, please go to: http://creativecommons.org/licenses/by-nc-nd/2.5/ 


\title{
An Investigation of the Factors Affecting the Successful Treatment of Organisational Issues in Systems Development Projects
}

\author{
N. F. DOHERTY \& M. KING \\ (The Business School, Loughborough University, \\ Loughborough, LE11 3TU)
}

Mailing Address:

Professor Malcolm King,

Loughborough University Business School,

Loughborough University of Technology,

Loughborough, LE11 3TU,

United Kingdom.

Telephone: 01509223119

Email: m.king@lboro.ac.uk

Fax:

01509223960

Email: n.f.doherty@lboro ac.uk 


\title{
An Investigation of the Factors Affecting the Successful Treatment of Organisational Issues in Systems Development Projects
}

Key Words: Systems development; Systems failure; Organisational issues; Organisational change; IT professionals; United Kingdom.

Running Head: Treating Organisational Issues

\begin{abstract}
A review of the relevant literature confirms the importance of treating organisational issues in order to avoid information systems development failures. To investigate how such issues are treated in practice and the factors associated with their successful treatment a large scale survey was conducted. A questionnaire was mailed to senior IS executives and over 600 responses were received. A majority of the respondents (60\%) perceived that organisational issues were more important than technical issues and a similar proportion reported treating these issues explicitly, although there was noticeable variation in the frequency that specific types of issue were treated. However, only $50 \%$ felt that organisational issues were successfully dealt with in more than $30 \%$ of the projects for which they were responsible. This proportion seems to be independent of the type of organisation or the general development approach adopted, but the results also indicate that using an approach to treating organisational issues which is explicit, frequent and covers a wide range of specific issues is associated with higher levels of success. These results suggest that senior IT executives need to go further in ensuring that the treatment of organisational issues is given greater time, resource and level of priority.
\end{abstract}




\section{Introduction}

Information technology is becoming all-pervasive in the modern organisation, increasingly affecting all aspects of the operations and strategic direction of an enterprise. Consequently, the introduction of IT into a company often brings about dramatic and wide ranging changes in the way in which a company is structured and the ways in which people work. These effects can result in radical shifts in job descriptions, salary structures, the role of middle management and the traditional divisions between functions (Hochstrasser \& Griffiths, 1991). Indeed, it is unlikely that an information system will operate successfully within its organisational environment unless the system, the organisation or both are modified (Wijnhoven and Wassenaar, 1990). It is, therefore, essential to anticipate the nature of this organisational impact prior to the system's implementation.

Historically information systems design has been preoccupied with technical issues at the expense of organisational. This is a dangerous strategy because there is a long stream of evidence to suggest that the treatment of organisational issues is perceived as more important than technical issues in determining the successful outcome of systems development projects (Lucas, 1975; Long, 1987; Hornby et al, 1992, Ewusi-Mensah \& Przanyski, 1994). Unfortunately there is also much evidence to suggest that organisational issues are still not properly treated during the systems development process (Eason, 1988; Hornby et al, 1992, Clegg et al, 1997a). Despite the recognised importance of organisational issues, very little empirical research has been conducted to establish how organisational issues are addressed, in general, or the factors that facilitate their successful treatment, in particular. To help fill this gap, a research project was initiated to explore IT executives' perceptions of the relative importance of organisational issues and to investigate the approaches that are typically adopted for their treatment. The preliminary results of this project, based on the 64 responses that were received from a small-scale exploratory study, have already been published (Doherty \& King, 1998). After critically appraising the results of this preliminary study, an enhanced questionnaire was developed and distributed to a more representative group that yielded a substantially larger sample (over 600 responses). This second, larger, data set facilitates the application of more statistical forms of analysis on a wider range of issues and this paper presents the results of an examination of the factors that affect the successful treatment of organisational issues in the systems development process.

The following section of this paper briefly summarises the findings of previous studies focusing upon the role and treatment of organisational issues. The research method is discussed in section three and the results are presented in the fourth section before their importance is discussed in the fifth section.

\section{Literature Review \& Research Motivation}

This section very briefly summarises the results of previous studies examining, first, the incidence of failure in systems development projects, second, relationships between the treatment of organisational issues and levels of systems failure and, finally, various 
approaches to treating organisational issues. In so doing, the justification for this piece of research will be established.

Before considering this literature it is important to note that there are differences in the terminology used. The phrase "organisational issues" itself is often not clearly defined and is sometimes expanded to "human and organisational issues". For the present this phrase will be simply taken to mean something that is not a technical systems problem, but a more precise definition is given as part of the research design. Similarly the words "address", "treat" and "treatment" are used interchangeably in the literature in relation to organisational issues, but following what appears to be the most recent trend this paper is using "treat" or "treatment" in this context with a more precise definition presented as part of the research design.

\subsection{Levels of Systems Failure}

Large numbers of information systems projects are either excessively over budget, months or years behind schedule, of poor quality, or simply fail to adequately satisfy users' requirements. Statistics on the success and failure of information systems are plentiful, and generally depressing. For example: Lyytinen \& Hirschheim (1987) estimate that about $50 \%$ of all IS projects fail; Kearney (1990) has found that only $11 \%$ of IT projects successfully deliver their planned benefits; and Hochstrasser \& Griffiths (1991) suggest that up to $70 \%$ of IS projects fail. Most recently, and certainly most worryingly, an extensive review of systems development practices by Clegg et al (1997a) found that: up to 90\% of all IT projects fail to meet their goals; $80 \%$ are late and over-budget and 40\% are abandoned. These statistics represent huge numbers of individual cases of abandoned, or under-performing, systems, which are reducing the operational and financial performance of many organisations.

\subsection{The Causes of Systems Failure: The critical role of Organisational Issues}

Concern with the topic of the treatment of organisational issues in the systems development process has come almost exclusively from the research conducted into the causes of information systems failure. A long stream of studies, including those conducted by Lucas (1975), Lyytinen \& Hirschheim (1987), Lederer \& Nath (1991), Hornby et al (1992), EwusiMensah \& Przasnyski (1994) and Ahn \& Skudlark (1997), have all identified inadequacies in the treatment of organisational issues as being a significant factor in cases of systems failure. Indeed, Long (1987) found that whilst only 10 per cent of failures in office automation applications are due to technical problems, 90 per cent can be accredited to organisational and managerial issues. Similarly, Ewusi-Mensah \& Przanski (1991) conclude that, when it comes to the factors that contribute to the abandonment of IS development projects, it is 'organisational issues which are the most widespread and dominant of factors'. When it comes to explaining why the treatment of organisational issues should contribute to incidences of systems failure, Clegg et al (1997a) suggest the following:

'Lack of attention to the human and organisational aspects of IT is a major explanatory factor [with regard to the high levels of systems failure] and is manifest in poor management generally, poor project management, poor 
articulation of user requirements, inadequate attention to business needs and goals, and a failure to involve users appropriately.'

The on-going, contributory role of organisational issues in the unacceptably high levels of systems failure has increased interest in the methods by which such issues are treated in the systems development process.

\subsection{The Treatment of Organisational Issues in the Systems Development Process}

There have been a number of attempts to ensure that organisational issues are satisfactorily treated in the systems development process. For example, in the past twenty years a number of specific methods, such as: ETHICS (Mumford 1986), Multiview (Avison \& WoodHarper, 1990) and SSM (Checkland, 1981), all of which have a stronger human and organisational orientation than traditional systems development methodologies, have been introduced. Alternative approaches to the treatment of organisational issues include: the modification of structured methods to take account of human factors (Lim et al, 1992); the adoption of a suite of tools to be used in conjunction with traditional methods (Clegg et al, 1996); the encouragement of user participation (Hornby et al, 1992) and participative design methods (Mumford, 1997). Unfortunately, despite these initiatives, the systems development process is still primarily a technology driven process (Clegg et al, 1997a; Poulymenako and Holmes, 1996). Additionally, the treatment of organisational aspects of systems development has been discussed in the risk management literature, where the need to consider the 'fit' between the system and the organisational structure, power relations and tasks has been highlighted (Lyytinen et al, 1996). However, it has been established that, in practice, IT professionals prefer technically orientated methods such as SSADM (Eason, 1988; Hornby et al, 1992; Mumford, 1997). The strong inference in much of the work in this domain is that the treatment of organisational issues in systems development projects is generally inadequate. There has, however, been little empirical research to quantify how successful IT professionals are in the treatment of organisational issues.

\subsection{Research Motivation and Objectives}

The above discussion has indicated that far too many systems development projects result in only partial success or even abandonment prior to completion. Furthermore, failure to adequately treat organisational issues has been repeatedly identified as the major contributory factor. Finally, it has been found that despite their acknowledged importance, the treatment of organisational issues in systems development projects is generally inadequate. Whilst all of these studies have increased our understanding of the role and importance of organisational issues, little empirical work has been conducted to establish how organisational issues are treated, in general, or the factors that facilitate their successful treatment, in particular.

To investigate this phenomenon further, a research project was initiated to explore the importance and treatment of organisational issues in systems development projects. It seemed important to find out how senior IT managers who have high level responsibility for running systems development projects view the situation. It could be that despite the 
consensus in the literature, they do not perceive organisational issues to be so important and so are not concerned about their treatment. On the other hand, they may see these issues as important but for some reason do not turn this concern into any form of action, or, possibly, they may attempt to take various forms of action and have found they are not very successful. These possibilities indicate it is important to know how senior IT managers view the importance of organisational issues, what different approaches they take to treating them and to what extent they believe they have been successful. Since it is unlikely there is no connection between these, it is also important to explore possible links between them.

By carefully analysing and extending these concepts, it was possible to construct a conceptual model, as shown in figure 1, to diagrammatically demonstrate how it was envisaged these links might be explored. This analysis suggested it was important to separate the possible approaches to treatment into two broad categories: one representing the overall formality and timing of the treatment; and the other measuring how often a range of distinct issues were treated. In a sense, this is making a distinction between when (and how) the issues are treated and what is treated, in terms of which issues. Next, it seemed possible there might be significant differences between different types of organisation. Combining these concepts with the perceived importance of organisational issues led to the four main constructs shown in the boxes on the left of the diagram. It was then considered each of these might have an influence on the success or otherwise of treating organisational issues, hence the four links into this fifth construct shown in the middle box. The last link from this to the box on the right of the diagram represents the generally accepted view that systems failure results from the lack of successful treatment of organisational issues. This was not explicitly investigated, having been adequately explored in previous studies. For example, the work of Hornby et al (1992), Ewusi-Mensah \& Przasnyski (1994) and Clegg et al (1997) have all identified inadequacies in the treatment of organisational issues as being a significant factor in cases of systems failure, and have all concluded that failure rates should diminish if treatment approaches were improved.

Insert Figure 1: 'Conceptual Framework for Success in Treating Organisational Issues' about here

In terms of figure 1, there are now two broad objectives to be operationalised within this study. The first is to examine senior IT managers' perceptions of the five constructs shown on the left and in the centre of the diagram and the second is to explore the relationships between the first four and the "success" concept in the centre. It was envisaged that by pursuing these objectives, it would be possible to provide advice and guidance to IT practitioners and executives with regard to the successful treatment of organisational issues. Hence, in simple terms, the two broad objectives of the research presented in this paper can be summarised as follows:

- To gain further insights into the treatment of organisational issues, in terms of its importance, different treatment approaches and levels of success. 
2 To investigate the factors which affect the successful treatment of organisational issues during the systems development process.

\section{Research Design}

The aim of this section is to review the process by which an initial research instrument was developed, validated and utilised before being enhanced for use in the wider, more representative, survey which is the focus of this paper.

\section{$\underline{3.1 \text { Instrument Development and Pre-testing }}$}

At the outset of the project it was necessary to propose a working definition for 'organisational issues', as no explicit definition existed. Strongly influenced by the work of Eason (1988), Clegg et al (1989) and Hornby et al (1992) the following definition was generated:

'Those issues which need to be treated during the systems development process to ensure that the individual human, wider social and economic impacts of the resultant technical system are likely to be desirable.'

Inherent in the use of the term 'treated', in this definition, is the concept of 'evaluation' followed by 'action'; a development team will have to evaluate a specific impact, prior to initiating appropriate action to ensure that the impact is desirable. For example, it might be necessary to modify the system's technical specification, or initiate a programme of organisational change, to ensure that all the system's organisational impacts are ultimately desirable. Indeed, in many instances there might be a cycle between evaluation and action; a specific impact is evaluated, some corrective action is taken and the situation is re-appraised to ensure that the resultant impact is desirable, and so on. In essence, the treatment of organisational issues is the mechanism by which the project team should match the capabilities afforded, and the constraints imposed, by the technical system to the requirements and characteristics of an organisation and its individual employees. Based upon the above definition, a wide range of issues, such as the impact of a system on an organisation's working practices, structure and performance could be classified as organisational, as could its impact the motivation and performance of individual employees.

To canvass the views and perceptions of a wide range of senior IT executives, on the treatment of organisational issues in systems development projects, a field survey was employed. Consequently, a draft questionnaire, which focussed upon the importance and treatment of organisational issues, was developed, based primarily on issues that had been highlighted through the literature review. This draft questionnaire was then thoroughly pretested with senior IT managers from five local companies for content validity, readability and general format. These managers were largely happy with the form and content of the questionnaire, although a number of interesting enhancements were suggested and ultimately accepted. In particular, the validation exercise resulted in the identification of three 
additional organisational issues, namely 'prioritisation of tasks', 'timing of implementation' and 'organisational disruption', as well as some important enhancements to the wording and ordering of questions.

The questionnaire was then distributed to a convenience sample of 88 named IT professionals in a wide variety of UK-based organisations, as part of a small scale, exploratory study. This exercise generated 64 useable responses that were of sufficient interest and importance to have been already published in their own right (Doherty \& King, 1998). In essence, this initial study constituted an extensive pilot study that allowed a number of important enhancements to be made to the questionnaire prior to the distribution of the main survey. Whilst the initial study produced many interesting results and reinforced the importance of organisational issues it could be criticised because of limitations with respect to its scale, sampling procedures and scope. Consequently, to effectively explore the stated research objectives, the survey instrument was thoroughly reviewed and significantly enhanced prior to utilising it in a far larger and more representative study. This review process consisted of re-examining the literature for any newer publications, as well as examining the responses to, and the statistical analysis of, the initial survey. For example, the responses to the 'additional comments' question on the original survey had alerted the researchers to the importance of re-engineering as an element of the organisational change associated with IT projects. Consequently, a new organisational issue, associated with the re-engineering of business processes was included in the revised questionnaire. Another significant enhancement was the introduction of a whole new section relating to the success of treatment, which was added to facilitate a wider variety of statistical analyses. The enhanced version of the questionnaire was then subjected to a further series of pre-tests, prior to its distribution.

\subsection{Variable Selection and Operationalisation}

This section aims to briefly describe each of the variables included in the enhanced questionnaire and demonstrate, where appropriate, their links to the existing literature. The questionnaire was divided into five sections, each of which is briefly discussed below:

1. Profile of Respondents: Respondents were asked to categorise their organisation in terms of size and the sector in which it primarily operates, using standard classifications. Furthermore, the respondents were asked to indicate the extent to which their organisations designed and coded their systems in-house, as opposed to using packages or external consultants. It was felt that this might strongly influence the treatment of organisational issues.

2. The Importance of Organisational Issues in the Systems Development Process: This section of the survey focused on the perceived importance of organisational issues. The work of Buchannan (1991) and Ewusi-Mensah \& Przanski (1994) had previously suggested that organisational issues might be more important than technical issues, in determining the ultimate success or failure of a systems development project. 
Consequently, the respondents were asked to compare the relative importance of organisational and technical issues, using a five item scale.

3. Approaches to the Treatment of Organisational Issues in the Systems Development Process: The third section considered the methods by which organisational issues are treated during a systems development project. This point is particularly important because, whilst previous research suggests that common development methodologies are poor at addressing organisational issues [Eason, 1988], it might be that such aspects are treated outside the framework of a specific methodology. The inclusion of six distinct approaches to the treatment of organisational issues was motivated by the work of many researchers. For example, the notion of implicit approaches was influenced by the work of Hornby et al (1992), Sauer (1993) has previously suggested the organisational impact analysis, whilst the fact that organisational issues might be treated rarely has been identified by, amongst others, Newman (1989).

4. The Frequency of treatment of Specific Organisational Issues: In addition to studying the treatment of organisational issues in general terms, it is also important to establish how frequently a variety of the most common organisational issues are treated in practice. Having established a working definition for organisational issues, the literature was thoroughly reviewed to identify all those issues that conformed to this definition. For example, the work of Cooper (1994) and Tolsby (1998) both highlight the cultural impacts of IT and consequently 'evaluating the cultural impacts of IT could be classed as an organisational issue. Ultimately, this exercise resulted in the identification of fifteen distinct issues, which could be categorised as organisational. Each of these was operationalised as a five point Likert scale, ranging from 'Always' [1] through to 'Never' [5]. A full list of the fifteen issues ultimately used in the full survey, together with their most important sources, is presented in table 1 . The fifteen issues have also been classified into four major groupings, namely organisational contribution, organisational alignment, transitional and human-centred issues, to indicate the class of impact primarily expected. It will be noted that the those classed as organisational contribution are more concerned with economic impacts, whereas those in organisational alignment tend to impact on the wider social aspects of the organisation, in contrast to the human centred ones which focus on individual human impacts. These classes are important, because they are the focal point of some important aspects of the analysis presented in section 4.2 .

Insert Table 1 'Organisational Issues Listed in Survey' about here

5. Levels of Success in the Treatment of Organisational Issues: To establish how successful organisations perceive themselves to be in the treatment of organisational issues, respondents were asked to consider the proportion of their projects in which they believed organisational issues were successfully treated. This could be considered a somewhat biased measure as those who try to treat many issues might well want to 
respond that they have been more successful. On the other hand, these respondents would be acutely aware of their overall success in development projects and unlikely to want to exaggerate the technical causes of any failures, so it was considered this question was a good surrogate for measuring treatment success.

Clearly, in completing the questionnaire, it was important that all the respondents had a shared understanding of the term organisational issue. To focus the respondent's minds on the meaning of the term organisational issue, prior to completing the survey, several examples of such issues were presented in the covering letter. Furthermore, the questionnaire included the 15 specific examples of such issues in a full-page spread which were clearly visible on commencement of the questionnaire.

\subsection{Data Collection Procedures}

Senior IS executives were chosen as the survey's 'key informant' (Venkatraman, 1989), as it was perceived that respondents would need a high degree of managerial responsibility for systems development projects to be able to comment knowledgeably about the treatment of organisational issues. The names of suitable executives were assembled from the most senior level of the British Computer Society's (BCS) membership list and the main survey was ultimately distributed to 3500 such individuals in UK-based organisations. It was envisaged that this sampling frame would be representative of those with senior management responsibilities for IS development projects, although it was not possible to investigate their spread through the UK economy before the mailing. Overall more than 600 valid responses were received from the 3500 questionnaires mailed out by BCS, representing a response rate of over $17 \%$ which is considered highly encouraging in terms of the normally expected responses to similar types of survey.

\subsection{Sample Characteristics and Evaluation of Non-response Bias}

The distribution of the respondents over the economy appeared reasonably representative. Of the valid respondents, $42 \%$ were employed in smaller organisations having less than 500 employees, 20\% were based in organisations with between 500 and 2000 employees and $38 \%$ in larger organisations with over 2000 employees. The responses were also found to have come from a large variety of organisational sectors, with organisations operating in the manufacturing, public, financial services and consultancy sectors particularly well represented. Finally, respondents were categorised in terms of their strategies for acquiring IT; each respondent estimated the proportion of systems that were designed and coded, inhouse, as opposed to being acquired from external sources (packages, consultants etc.). The sample is skewed to those organisations who rely upon external sources; roughly half the respondents (44\%) indicated that less than a quarter of their design and coding was done in-house. The remainder of the responses were split roughly equally between those organisations which did their coding in-house on close to half their projects (27\%) and those designing and coding in-house for more than three-quarters of their IS projects (29\%).

When undertaking survey-based research, there is always the danger that the results will be undermined, or even invalidated, through the introduction of bias. It is, therefore, important 
that active measures are taken to reduce the likelihood of bias having any such negative affects. In this research the content validity of the constructs has been established through the process of initially linking the variables to the research literature and then refining them through an extensive and comprehensive process of pre-testing and pilot testing. Any sample bias introduced through the loss of data from non-respondents is often harder to establish, as this data is not easily obtainable. However, it is possible to approximate this bias by comparing the answer patterns of early and late respondents (Armstrong \& Overton, 1982). Consequently, in this study, non-response bias was tested by comparing "early" and "late" respondents along both of the key dimensions; frequency of treatment and importance of organisational issue. The statistical approach was an independent samples t-test which indicated that there were no significant differences in the profile of responses at the $10.0 \%$ level. These results imply that no detectable response bias exists in the sample and that the results are generalisable within the boundary of the sample frame.

\section{Research Results}

The 593 usable questionnaire responses ultimately received were first entered into a spreadsheet, prior to transference to the statistics package SPSS, where a variety of statistical techniques were applied. This section presents a description of the application of the analytical tools, in addition to a detailed discussion of the results of the analysis. To make the discussion more meaningful the research findings are related to the two specific research objectives proposed earlier.

\subsection{The Treatment of Organisational Issues}

The aim of this section is to present a descriptive summary of the major findings with regard to the treatment of organisational issues.

The Importance of Organisational Issues: Whilst much previous research has indicated that most systems development methodologies focus on technical issues at the expense of organisational issues, a significant majority of the respondents to this research felt that organisational issues are more important than technical issues. The majority of the respondents $(60 \%)$ perceived that organisational issues were either 'the most important issue', or 'more important than technical issues', whilst a further $34 \%$ felt that organisational issues were 'of equal importance to technical issues'. Therefore, only $6 \%$ of the respondents considered technical issues to be of more importance than organisational issues. Figure 2 provides a full break down of the responses to this question.

Insert Figure 2: 'The relative importance of organisational issues' about here

These results are particularly significant in the context of previous research. Whilst previous studies (for example: Lucas (1975); Long (1987); Ewusi-Mensah \& Przasnyski (1994)) have identified the importance of organisational issues, there is evidence to suggest that this message has not been recognised within the IT community, For example, in conclusion to 
their study of the treatment of human and organisational issues in information systems development Hornby et al (1992) commented:

'Finally, it is clear that much work needs to be done if attitudes are to change such that human and organisational issues are recognised as important contributors to the success of systems outcomes'.

This survey has provided clear evidence that the attitudes of one highly influential group, namely senior IT executives, is now changing in a positive direction, and hopefully this recognition will begin to influence the treatment of organisational issues in future systems development projects. In terms of the questions posed under the research motivation, section 2.4, it now seems clear that lack of awareness or concern over these issues is not a major contributor to the lack of success.

The Overall Treatment Approach: All respondents to the survey were asked to identify which of a range of approaches to the treatment of organisational issues best matched the one that they typically utilised. The range of options offered included, 'rarely considered' and 'implicitly considered', as well as a selection of explicit approaches to their treatment. A surprisingly high proportion of the responding organisations, treat organisational issues explicitly (60\%), either, during the feasibility study, during the requirements analysis, throughout the project, or, through an independent organisational impact analysis. Those organisations which treat organisational issues implicitly are still, however, the largest single category with $27 \%$ of the responses, and a worrying $13 \%$ of the responding organisations rarely consider such issues. The complete breakdown of these figures is presented in figure 3.

Insert Figure 3: 'The Treatment of organisational issues' about here

The finding that $39 \%$ of respondents claim to treat organisational issues explicitly, during either the feasibility study or the requirements analysis, is important in the context of previous research which suggested that when such issues are considered, it is typically relatively late in the development process (McClaren et al, 1991, Lim et al, 1992). This result is encouraging, as it may suggest that a significant number of organisations are now recognising that organisational issues must be treated fairly early in the development cycle, when they can be treated in a proactive manner. This result combined with the fact that $87 \%$ reported some regular consideration of these issues suggests that senior IT managers are ensuring that their concern about these issues is turned into some form of action and so, it terms of the research questions, it is not lack of action that is a major contributor to the lack of success

Whilst $98 \%$ of the survey respondents were happy to select one of the six pre-defined classes of treatment approach, as identified in figure 3, the remainder took the opportunity to define their own alternative treatment approach. The alternative approaches could broadly be 
categorised as either strategic or re-active. The strategic approach suggests that organisational issues are primarily treated through the information systems planning process rather than during individual information systems projects, whilst the re-active approach suggests that specific organisational issues are treated only as and when problems arise.

The Frequency of Treatment of Organisational Issues: The findings, presented in table 2, show the average frequency with which each of the four major groups of organisational issues is treated. These were calculated by taking a simple average, using the Likert scale data, for each of the organisational issues associated with a specific class of issue, see table 1 for details. Before doing this, however, it was necessary to confirm that all the variables, within a specific group, measure the same underlying construct. This confirmation was achieved by undertaking internal reliability tests, using the 'Cronbach alpha' measure; all four comfortably exceeded the threshold value of 0.60 (Hair et al, 1997; p 118). An inspection of the data presented in table 2 suggests there are differences between the frequencies with which each of the groups of issues is treated. Bearing in mind a score of 1 indicates always, organisational contribution and transitional issues are treated more often than not, whereas for the alignment issues the reverse is reported and individual issues come in between. As the scores run on a 1 to 5 scale, these differences shown by the means in table 2 look quite significant. Indeed, the results of a paired t-test indicate that all four means are significantly different at the $5 \%$ level, and all but the means for the organisational contribution and transitional issues categories are also significantly different at the $1 \%$ level.

Insert Table 2 'Frequency of Treatment for Classes of Organisational Issue' about here

In terms of their relative positions, it can be seen that the organisational contribution issues being treated most commonly, whilst the organisational alignment issues are treated least frequently. Intuitively these finding make sense as there must be an expectation that the contribution must be evaluated and managed, in the vast majority of systems projects, irrespective of size and complexity. By contrast, it might be the case that for some systems projects, especially smaller and simpler projects, the likelihood of significant cultural and structural impacts is negligible, and consequently the organisational alignment issues can be safely ignored. However, the relative lack of attention to treating the issues in the organisational alignment category may be part of the explanation for the lack of eventual success.

The Successful Treatment of Organisational Issues: Respondents were asked to consider only those systems development projects for which they were directly or indirectly responsible and indicate the percentage of those in which organisational issues were treated to their satisfaction. The respondents were offered a choice of six categories and the results are presented in figure 4.

Insert Figure 4: 'The Successful Treatment of Organisational Issues' about here 
It will be seen that the distribution is rather skewed towards the low categories, peaking at nearly $40 \%$ who felt that organisational issues were only successfully treated in between $10 \%$ and $30 \%$ of all projects. This distribution is a further vindication of the question used, as it now seems very unlikely that a significant number of respondents are reporting inflated perceptions of their success in treating these issues.

Given the distribution that has emerged, for subsequent analysis and further discussion it is easiest to merge some of the categories. A simple and useful division is to consider all those who thought that organisational issues were successfully treated in less than $30 \%$ of projects (or in just less than a third of all projects) as opposed to those they were successful in a higher percentage of cases. These two categories, of successful in $<30 \%$ and successful in $>30 \%$, each account for almost exactly half of the respondents. Several subsequent tests will be based on dividing the respondents into these two categories, but in some cases the data has been examined in finer detail using the four categories formed by just merging the top two and bottom two categories.

Although it would have been surprising if organisational issues were being successfully treated in all projects, the finding that almost half of the respondents perceived that organisational issues were satisfactorily treated in less than a third of systems development projects is of distinct concern. These results are particularly interesting when considered in light of the finding that $60 \%$ of the respondents believe organisational issues to be of more importance than technical issues when determining the successful outcome of systems development projects. These findings go a long way to explaining the high levels of systems failures identified in previous studies (for example: Lyytinen \& Hirschheim (1987); Kearney (1990); Hochstrasser \& Griffiths (1991) and Clegg et al (1997a)).

\subsection{An Analysis of the Determinants of Successful Treatment of Organisational Issues}

The level of success achieved in the treatment of organisational issues, as summarised in section 4.1, suggests that there is high degree of variability. The aim of this section is to pursue the second research objective, which is to explore the links leading into this concept, shown on the left hand side of figure 1 , and thereby to investigate whether a variable can be identified that is affecting, and may possibly explain, the differences in levels of success. The technique selected to explore this issue is the chi-squared method, which is appropriate because in all the following cases the variables are categorical. It should, however, be noted that in some instances it has been necessary to compress categories to ensure that the expected frequencies in every cell of the contingency table are greater than five ( a prerequisite of the Chi-squarded method).

Profile of Respondent: A chi-squared analysis indicated that neither the size of an organisation, or the sector in which it primarily, operates influences the successful treatment of organisational issues. 
It might be hypothesised that organisations adopting packages might be more likely to successfully treat organisational issues than those which develop tailor-made solutions. The reasons for this hypothesis could be twofold. Firstly, as the original software designers have already addressed most technical issues, the project team has more time to concentrate upon organisational issues. Conversely it could be that when using packaged software the scope for matching the software to the organisation is reduced and therefore it is necessary to match the organisation to the software and therefore organisational issues predominate. However, the results of the chi-squared test, presented in Table 3, indicate that there is no discernible relationship between the systems development approach favoured and success in the treatment of organisational issues.

\section{Insert Table 3: 'Development Approach v Success' about here}

The Importance of Organisational Issues: It seems plausible that those senior IS managers who acknowledge the importance of organisational issues might ensure that sufficient time and resources are devoted to their successful treatment. Hence, it is reasonable to hypothesise that perceived success in treating organisational issues is dependent on perceptions of the importance of these issues. Consequently, a chi-squared test was also employed to investigate this hypothesis.

Insert Table 4: 'Importance of Organisational Issues v Success' about here

The results of the chi-squared analysis presented in table 4 show that different perceptions of the importance of organisational issues are translated into marked differences in terms of the perceived success of their treatment. In fact, this result is significant at the $99 \%$ level, so it is important to explore the form of the relationship further. It is easy to see from table 4 that those managers who perceive organisational issues to be of less importance than technical issues are likely to succeed in their treatment in a smaller proportion of projects. Also those who think organisational issues are most important are achieving the highest proportion of success. Although not surprising, this is an important result, which confirms a plausible hypothesis.

The Overall Treatment Approach: It was envisaged that those organisations that treat organisational issues explicitly might be more successful in their treatment than those which don't. Consequently, a chi-square test was employed to test this hypothesis.

Insert Table 5: 'Treatment of Organisational Issues v Success' about here

The results of the chi-squared analysis presented in table 5 demonstrate that there are highly significant differences in the level of success achieved by organisations adopting different treatment approaches. Statistically the result is significant at the $99.9 \%$ level indicating a very important dependence. The figures presented in table 5 suggest that there are both associations between those organisations which treat organisational issues explicitly with 
success and those organisations which treat organisational issues rarely with failure. In particular, there appears to be a very strong link between those who rarely consider them and the failure to treat them successfully, which is hardly a surprising result. However, a rather more interesting result emerges if the first four categories in table 5 are merged and considered as various forms of explicit treatment. For those with explicit treatment, there are then 136 in the less successful category and 209 in the more successful category. Comparing this with those treating the issues implicitly, which have an almost equal number (78 to 79) in the two different success categories, it is clear that using an explicit approach is associated with a much higher proportion of success.

The Frequency of Treatment: It was hypothesised that the successful treatment of organisational issues might be predicated on the treatment of a wide range of issues, in the vast majority of systems development projects. To test this hypothesis, an analysis of variance was conducted to explore the relationship between the average frequency of treatment, for each of the four classes of organisational issue, and the resultant levels of success.

Insert Table 6: 'The Relationship between Frequency of Treatment and Success in treatment of Organisational Issues' about here

The results of this analysis, presented in table 6 indicate that there is a statistically significant relationship between these variables. Remembering that the means in table 6 represent average frequency of treatment with 1 as "always" and 5 as "never" (so the larger averages represent less frequent treatment), an inspection of the data indicates that success in the treatment of organisational issues is associated with higher frequencies of treatment for all four categories of organisational issue. This result therefore underpins the importance of treating a wide range of organisational issues, in a high proportion of systems development projects.

\section{Discussion: The Successful Treatment of Organisational}

\section{Issues}

The results presented in the previous section are based on a large scale survey of senior IT managers and build on the findings of a previous small scale exploratory research [Doherty \& King, 1998]. The size of the sample has enabled more detail to be explored and more relationships investigated, leading to greater insight and more confidence in suggesting implications, from both a practitioner and research perspective.

The results confirm that, in general, senior IT managers now perceive the importance of organisational issues, but that there is a high degree of variability in the approaches adopted for their treatment and the high degree of variability with which specific issues are treated. 
It has also been empirically established that organisational issues are not perceived to have been successfully treated in the majority of information systems development projects. This result is significant because whilst many previous studies have attempted to quantify the perceived importance of organisational issues [Long, 1987; Ewusi-Mensah \& Przanski,1991; Doherty \& King, 1998], no previous research has been identified that explicitly explores the extent to which senior IT executives perceive their project teams are successful in their treatment. The primary reasons for organisations having problems with the treatment of organisational issues are likely to be because of their intangible and politically sensitive nature.

An analysis of the determinants of success in the treatment of organisational issues has provided a number of important insights. For example, it has established that it is not the characteristics of the organisation that increase, or decrease, the likelihood of attaining success nor does it depend on the development approach adopted. However, it has been demonstrated that perceiving organisational issues to be important and adopting treatment approaches that are explicit, frequent and cover a wide range of issues will lead to greater perceptions of success, which, it is argued, indicates actual greater organisational success.

The general implication of the literature in this domain is that despite their acknowledged importance, organisational issues are often poorly treated primarily because IT professionals do not believe that they have the necessary skills, tools and experience to effectively treat them. Furthermore, such inadequacies in the treatment of organisational issues are now strongly implicated in the unacceptably high levels of information system failure that greatly reduce the organisational contribution of information technology. Consequently, this research, which provides insights into ways of improving the treatment of organisational issues, is critical as it may have significant implications for reducing the level of failure in information systems projects. Probably the most important implication for IT managers and practitioners is that they must urgently take steps to improve their performance in the treatment of organisational issues. More specifically, project managers should look to adopt explicit methods for the treatment of organisational issues, whether this is within or outside of the application of a specific development methodology. Furthermore, it is important that managers treat a wide range of issues in the majority of their systems development projects. To this end, the taxonomy of organisational issues, presented in table 1, might act as a useful framework for establishing the scope and content of an explicit treatment approach. Whilst simply identifying the issues to be treated is a very necessary step, it is not sufficient. Senior IT executives must also ensure that the treatment of organisational issues is given adequate time, resources and perhaps most importantly the highest level of priority.

From the researchers' perspective, this study has developed a range of different variables and constructs that can be usefully adopted in future studies. However, research into the adoption of innovative technology, within the organisational context, is an ambitious undertaking, and therefore contains a number of inherent limitations. In particular, the adoption of the survey format restricts the range of issues and constructs that can be explored, the selection of a fairly narrow sampling frame reduces the generalisability of the results and finally there is potential response bias associated with the 'single-informant'. 
These limitations highlight the need for follow-up studies to be conducted employing different methods, and targeting different populations. More specifically, in-depth studies could be undertaken to explore: how organisational issues are treated, both in terms of methods and timing; who is responsible for conducting their treatment; the resultant success of such treatments; and the factors which are inhibiting the effective treatment of organisational issues. Finally, it is important that future research seeks to identify best practices, methods and techniques, which can be disseminated to the user community to improve the practice of systems development in an increasingly complex business environment.

\section{Concluding Remarks}

This paper presents significant new evidence about the importance and treatment of organisational issues, based on one of the few large scale and wide ranging empirical studies, to be conducted in this domain. It has been confirmed that that organisational issues are perceived to be of more importance, than technical issues, in determining the ultimate success of information systems development projects. Moreover, it has been shown that success in the treatment of organisational issues is predicated upon perceiving them to be important and then adopting explicit approaches, which focus upon a wide range of specific issues. Such insights are of particular importance at this moment in time, when organisations are becoming increasingly dependent upon IT, yet still experience significant problems with respect to its development and implementation. Whilst the findings will be of most significance to those organisations operating within the UK, it is likely that they will also be of interest to a wider audience, as systems failure continues to be a universal problem.

\section{Acknowledgements}

The authors would like to thank all those IT professionals who took the time and trouble to respond to the questionnaire, especially those who were involved in the pre-testing exercise. They are also extremely grateful to the BCS who were instrumental in the execution of this research. 


\section{References}

Ahn, J. \& Skudlark, A (1997) "Resolving conflict of interests in the process of an information system implementation for advanced telecommunication services", Journal of Information Technology, Vol. 12, pp. 3-13.

Armstrong, J. S. \& Overton, T. A.(1982) 'Estimating non-response bias in mail surveys', in Marketing Research: Applications and Problems, eds. Jain, A., Pinson, C. \& Ratchford, B., John Wiley \& Sons, Chichester.

Avison, D. \&Wood-Harper, A. T. (1990) Multiview: An Exploration in Information Systems Development, McGraw-Hill, Maidenhead.

Bloomfield, B. \& Coombs, R. (1992) "Information technology, control and power: The centralisation and decentralisation debate re-visited, Journal of Management Studies, Vol. 29, No. 4, pp 459-484.

Buchanan, D. 1991, Figure-Ground Reversal in Systems Development \& Implementation: From $\mathrm{HCl}$ to OSI. in Nurminen, M. \& Weir, G. (eds) Human Jobs and Computer Interfaces, North Holland, 213-226.

Checkland, P. B. (1981) Systems Thinking, Systems Practice. Wiley. Chichester.

Clegg, C., Warr, P., Green, T., Monk, A., Allison, G. \& Landsdale, M. (1989), People and Computers: How to evaluate your company's new technology, Ellis Horwood, Chichester.

Clegg, C., Coleman, P., Hornby, P., McClaren, R., Robson, J., Carey, N. \& Symon, G. (1996) "Tools to incorporate some psychological and organisational issues during the development of computer-based systems", Ergonomics, Vol. 39, No. 3, pp. 482-511.

Clegg, C., Axtell, C., Damadoran, L., Farbey, B., Hull, R., Lloyd-Jones, R., Nicholls, J. Sell, R. \& Tomlinson, C. (1997a) "Information Technology: a study of performance and the role of human and organizational factors", Ergonomics, Vol. 40 No. 9, pp. 851-871.

Clegg, C., Carery, N., Dean, G., Hornby, P. \& Bolden, R. (1997b) Users' reactions to information technology: Some multivariate models and their implications, Journal of Information Technology, 12: 15-32.

Cooper, R. B., 1994, 'The inertial impact of culture on IT implementation', Information \& Management, Vol. 27, pp. 17-31.

Davenport, T. H. (1993) Process Innovation: Re-engineering Work through Information Technology, Harvard Business School Press, Boston, Massachusetts.

Doherty, N. F. \& King, M., (1998) "The consideration of organizational issues during the systems development process: an empirical analysis", Behaviour \& Information Technology, Vol 17, No. 1 , pp 41-51.

Doherty N.F. and King M. (2000) "The treatment of organisational issues in systems development projects: the implications for the evaluation of IT investments". In Proceedings of the Seventh European Conference on IT Evaluation (BROWN A and REMENYI D, Eds), 49-58, MCIL, Reading.

Eason, K., (1988), Information Technology and Organizational Change, Taylor \& Francis, London.

Ewusi-Mensah, K. \& Przasnyski, Z. (1991) "On Information Systems Project Abandonment: An Exploratory Study of Organizational Practices", MIS Quarterly, March, pp. 67-85.

Ewusi-Mensah, K. \& Przasnyski, Z. (1994) "Factors Contributing to the Abandonment of Information Systems Development Projects", Journal of Information Technology, Vol. 9, pp. 185-201.

Fitzgerald, G. (1998) "Evaluating information systems projects: a multidimensional approach", Journal of Information Technology, Vol 13, pp 15-27. 
Hair, J, Anderson, R., Tatham, R. \& Black, W. (1997). Multivariate Data Analysis, Prentice Hall, New Jersey.

Hochstrasser, B. \& Griffiths, C. (1991) Controlling IT Investment, Chapman Hall, London.

Hornby, C., Clegg, C., Robson, J., McClaren, C., Richardson, S. \& O'Brien, P. (1992) "Human \& Organizational Issues in Information Systems Development", Behaviour \& Information Technology, Vol. 11, No. 3, pp. 160-174.

Kearney, A. T. (1990), Barriers to the successful application of Information Technology, DTI \& CIMA, London.

Lederer, A. L. \& Nath R. (1991) "Managing Organizational Issues in Systems Development", Journal of Systems Management, Vol. 24, No. 11, pp. 23-27.

Lim, K., Long, J. \& Silcock, N. (1992) "Integrating Human Factors with the Jackson System Development Method: An Illustrated Overview", Ergonomics, Vol. 35, No. 10, pp. 1135-1161.

Long, R. J. (1987), New Office Information Technology: Human and Managerial Implications, Croom Helm, London.

Lucas, H. C. (1975), Why information systems fail, Columbia University Press, New York.

Lyytinen K. and Hirschheim R. (1987) "Information Systems Failures: A Survey and Classification of the Empirical Literature", Oxford Surveys in Information Technology. Vol. 4, pp. 257-309.

Lyytinen K., Mathiassen, L. \& Ropponen, J. (1996) "A framework for software risk management", Journal of Information Technology, Vol. 11, pp.275-285.

McClaren, C., Hornby, C., Robson, J., O'Brien, P. Clegg, C., and Richardson, S. (1991) Systems Design Methods: The Human Dimension, DECpress, Reading.

Markus M. and Robey D. (1983) The Organisational Validity of Management Information Systems. Human Relations. 36(3), 203-226.

Mumford, E. (1986), Using computers for business success: The ETHICS method, Manchester Business School, Manchester.

Mumford, E. (1997), "The reality of participative systems design; contributing to stability in a rocking boat", Information Systems Journal, Vol. 7, No. 4, pp. 309-321.

Nath, R. (1989) "Associations between user training and information systems success", International Journal of Information Management, 9 pp 259-265.

Newman, M. (1989) "Some fallacies in information systems development", International Journal of Information Management, Vol. 9, pp 127-143.

Poulymenakou, A.\& Holmes, A. (1996) "A Contingency framework for the investigation of information systems failure", EJIS, Vol. 5, pp. 34-46.

Raymond, L., Pare, G., and Bergeron, F. (1995) Matching information technology and organisational structure: an empirical study with implications for performance. European Journal of Information System, 4, 3-16.

SAUER C (1993) Why Information Systems Fail: A Case Study Approach, Alfred Waller, Henley.

Stebbins, M., Sena, J. \& Shani, A. (1995) "Information Technology and Organisation Design" Journal of Information Technology. 10, pp 101-113.

Tolsby, J., 1998, 'Effects of organisational culture on a large scale IT introduction effort', European Journal of Information Systems, Vol. 7, pp. 108-114.

Venkatraman, N. (1989) "The Strategic Orientation Of Business Enterprises - The Construct, Dimensionality, and Measurement", Management Science, Vol 35 No 8, pp. 942-962.

Wijnhoven, A. B., and Wassenaar, D. A. (1990) "The Impact of IT on Organizations: The State of the Art", International Journal of Information Management, Vol. 10, pp. 35-53. 


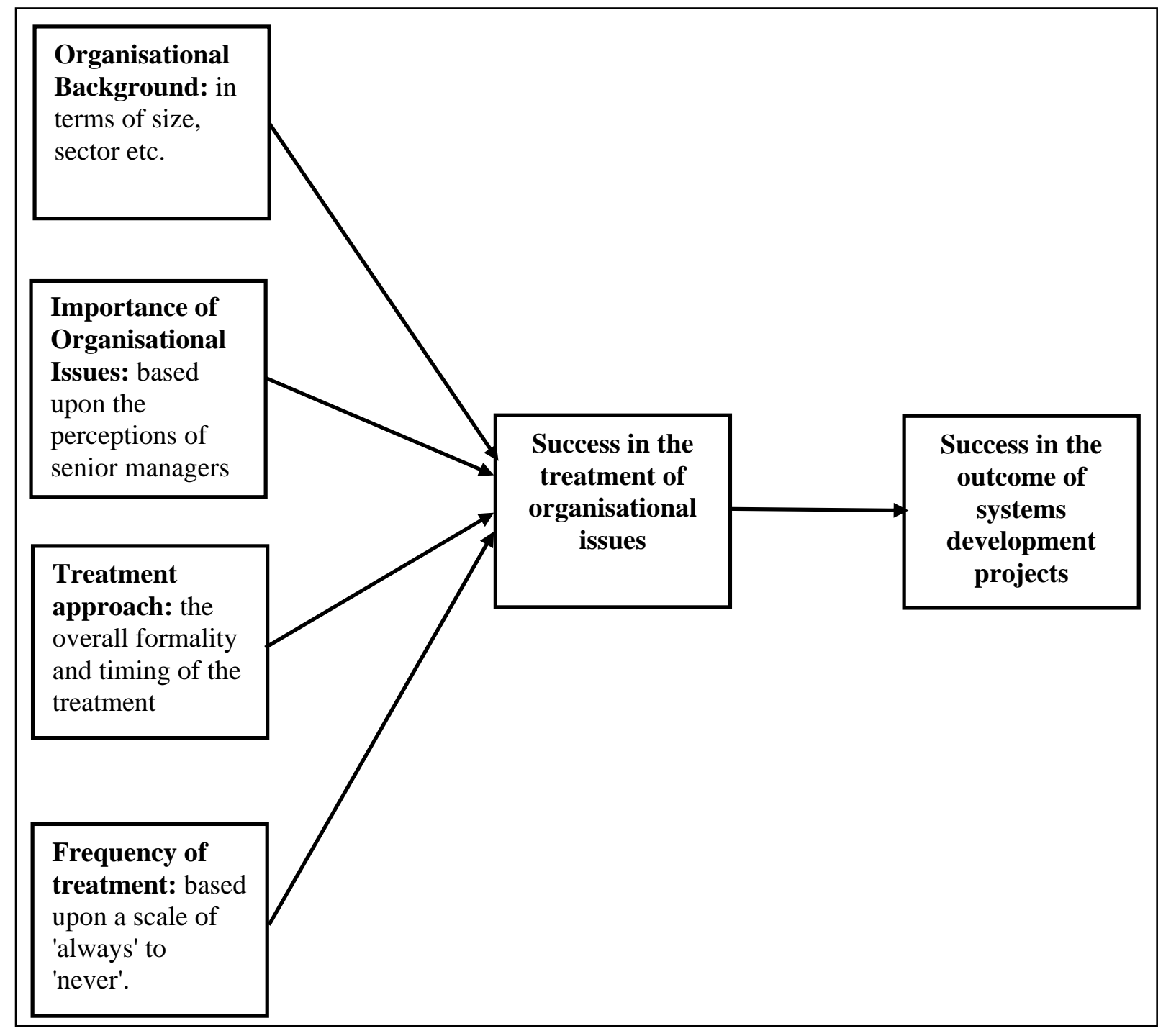

Figure 1: Conceptual Framework for Success in Treating Organisational Issues 


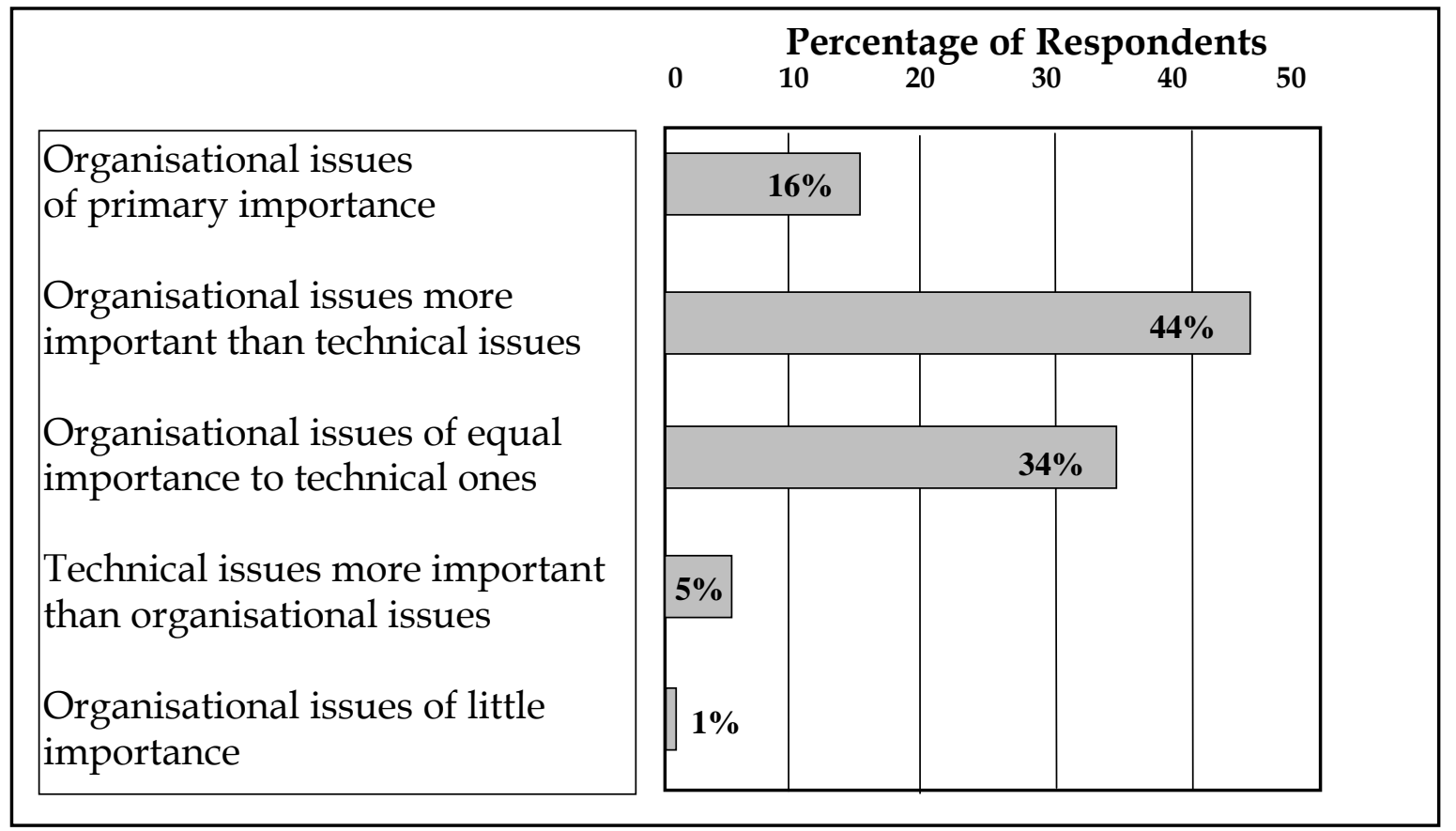

Figure 2: The Relative Importance of Organisational Issues 


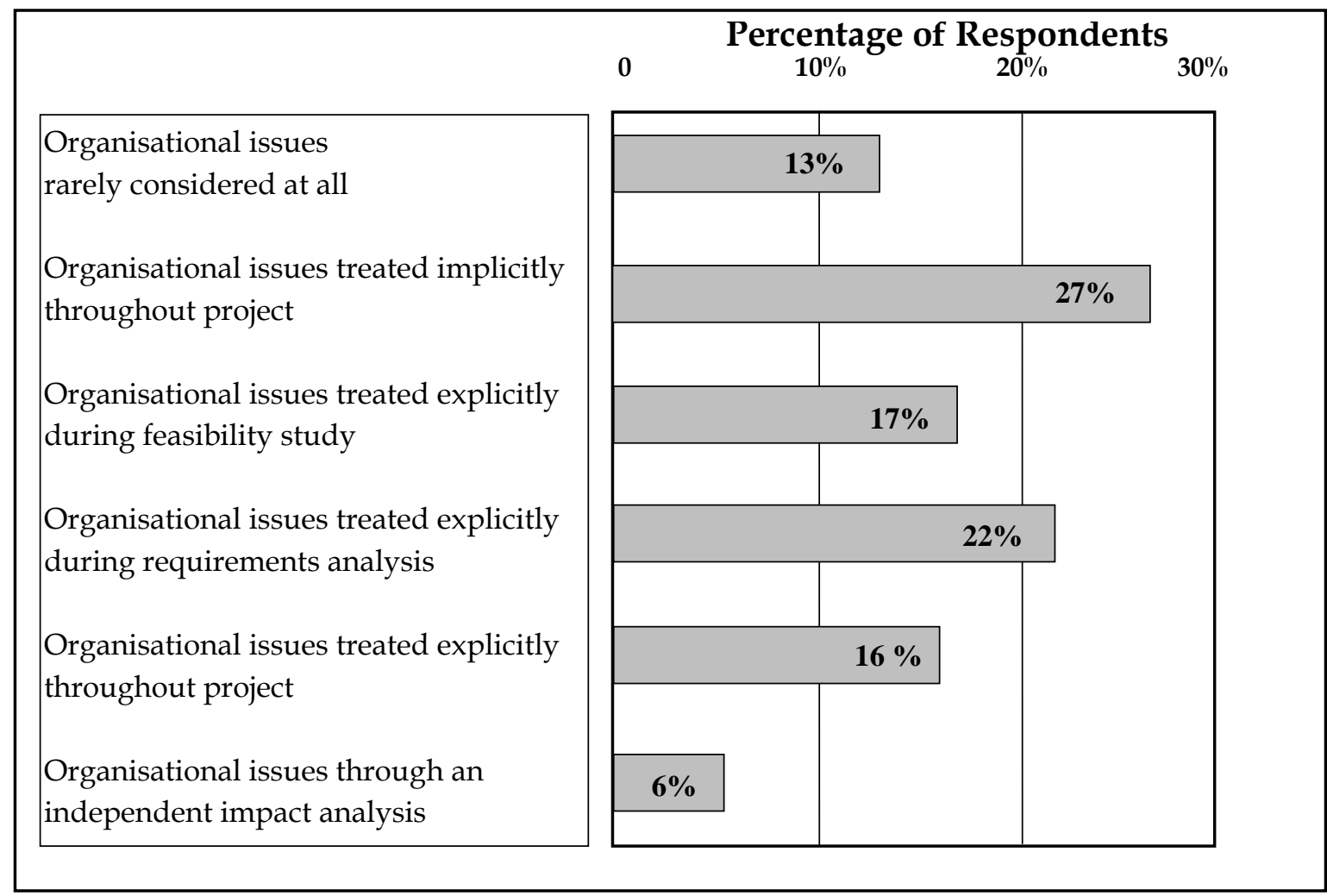

Figure 3: Approaches for the Treatment of Organisational Issues 


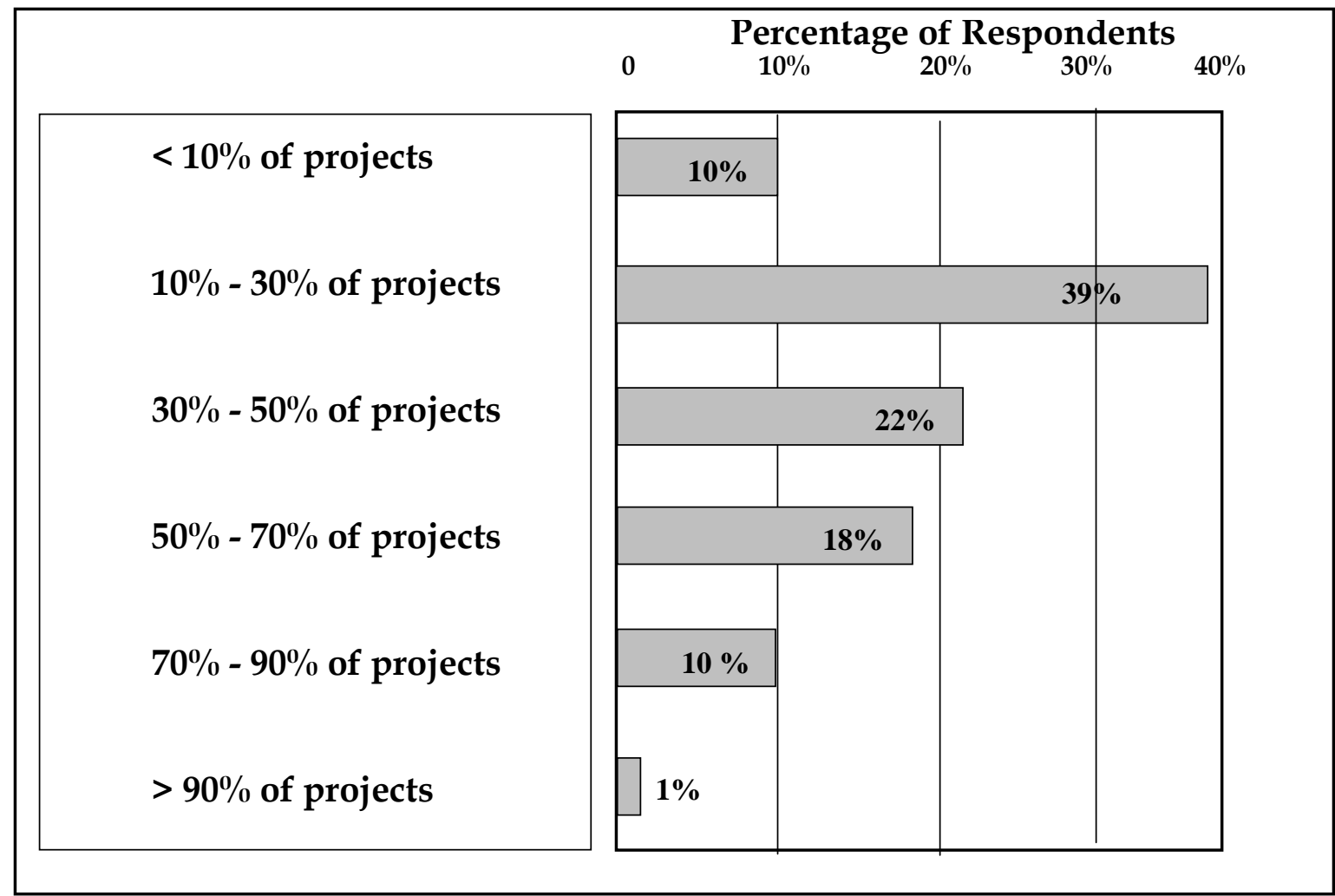

Figure 4: Successful Treatment of Organisational Issues 
Table 1: Organisational Issues Listed in Survey

\begin{tabular}{|c|c|c|c|}
\hline \multicolumn{2}{|c|}{ Category } & \multirow{2}{*}{$\begin{array}{l}\text { Specific Issues } \\
\text { Assessment of costs and benefits }\end{array}$} & \multirow{2}{*}{$\begin{array}{l}\text { References } \\
\text { Fitzgerald(1998) }\end{array}$} \\
\hline \multirow[t]{5}{*}{1} & & & \\
\hline & \multirow{4}{*}{$\begin{array}{l}\text { Contribution }(\boldsymbol{O C}) \text { : These } \\
\text { issues related to the extent } \\
\text { to which a proposed system } \\
\text { will make a significant } \\
\text { positive contribution to the } \\
\text { economic and operational } \\
\text { performance of the } \\
\text { organisation. }\end{array}$} & $\begin{array}{l}\text { Alignment with information systems } \\
\text { strategy }\end{array}$ & Fitzgerald(1998) \\
\hline & & $\begin{array}{l}\text { Prioritisation of tasks, in line with } \\
\text { organisational needs }\end{array}$ & Doherty \& King (1998) \\
\hline & & $\begin{array}{l}\text { Assessment of future needs of } \\
\text { organisation }\end{array}$ & Doherty \& King (1998) \\
\hline & & Re-engineering of business processes & Davenport (1993) \\
\hline \multirow[t]{4}{*}{2} & \multirow{5}{*}{$\begin{array}{l}\text { Human Centred Issues } \\
\text { (HCI): This category } \\
\text { focuses on individual } \\
\text { human issues that can affect } \\
\text { the success or otherwise of } \\
\text { the system's uptake. }\end{array}$} & Consideration of training requirements & Nath (1989); Clegg et al (1997a) \\
\hline & & $\begin{array}{l}\text { Assessment of health \& safety / } \\
\text { ergonomic implications }\end{array}$ & Clegg et al (1997a) \\
\hline & & Evaluation of user motivation / needs & $\begin{array}{l}\text { Clegg et al (1996) Markus \& } \\
\text { Robey (1983) }\end{array}$ \\
\hline & & $\begin{array}{l}\text { Assessment of implications of user } \\
\text { working styles / IT skills }\end{array}$ & $\begin{array}{l}\text { Clegg et al (1997b); Markus \& } \\
\text { Robey (1983) }\end{array}$ \\
\hline & & $\begin{array}{l}\text { Consideration of job redesign } \\
\text { implications }\end{array}$ & Eason (1988); Hornby et al (1992) \\
\hline \multirow[t]{2}{*}{3} & $\begin{array}{l}\text { Transitional Issues (TI): } \\
\text { This category is concerned } \\
\text { with those practical }\end{array}$ & $\begin{array}{l}\text { Consideration of timing of } \\
\text { implementation }\end{array}$ & Doherty \& King (1998) \\
\hline & $\begin{array}{l}\text { transitional issues which } \\
\text { might affect successful } \\
\text { implementation. }\end{array}$ & $\begin{array}{l}\text { Assessment of organisational } \\
\text { disruption }\end{array}$ & Doherty \& King (1998) \\
\hline & \multirow{3}{*}{$\begin{array}{l}\text { Organisational Alignment } \\
(\boldsymbol{O A}) \text { : This group of issues } \\
\text { focused upon the extent to } \\
\text { which a proposed system } \\
\text { and wider social aspects of } \\
\text { the host organisation are } \\
\text { matched. }\end{array}$} & Impact on organisational structure: & $\begin{array}{l}\text { Raymond et al (1995); Stebbins et } \\
\text { al (1994) }\end{array}$ \\
\hline & & $\begin{array}{l}\text { Implications for organisational } \\
\text { culture. }\end{array}$ & Cooper (1994); Tolsby (1998) \\
\hline & & Impact on distribution of power & $\begin{array}{l}\text { Bloomfield \& Coombs (1992); } \\
\text { Poulymenakou and Holmes } \\
\text { (1996). }\end{array}$ \\
\hline
\end{tabular}


Table 2: Frequency of treatment for Classes of Organisational Issue

\begin{tabular}{lllll}
\hline Class of Organisational Issue & Minimum & Maximum & Mean $(\mu)$ & S D $(\sigma)$ \\
\hline Organisational contribution issues & 1.00 & 4.60 & 2.4284 & .7288 \\
Transitional issues & 1.00 & 5.00 & 2.4941 & 1.0208 \\
Human-centred issues & 1.00 & 5.00 & 2.7608 & .7677 \\
Organisational alignment issues & 1.00 & 5.00 & 3.3596 & .8992 \\
\hline
\end{tabular}

Note: a response of 1 indicates always, whilst a response of 5 indicates never

Table 3: The Relationship between System Type and Success in treatment of Organisational Issues

\begin{tabular}{lccc}
\hline & $\begin{array}{l}\text { Successful in } \\
<30 \% \text { of } \\
\text { projects }\end{array}$ & $\begin{array}{l}\text { Successful in } \\
>30 \% \text { of } \\
\text { projects }\end{array}$ & \\
\hline $0-30 \%$ of systems tailor-made & $\mathbf{1 2 8}(121.1)$ & $\mathbf{1 2 0}(126.9)$ & 248 \\
$30-70 \%$ of systems tailor-made & $\mathbf{7 5 ( 7 4 . 7 )}$ & $\mathbf{7 8}(78.3)$ & 153 \\
$70-100 \%$ of systems tailor-made & $\mathbf{7 0}(77.2)$ & $\mathbf{8 8}(80.8)$ & 158 \\
& 273 & 286 & 559 \\
\hline
\end{tabular}

Not significant at the $10.0 \%$ level; $\chi^{2}=2.07<4.61=\chi^{2}(0.1)$, $2 \mathrm{df}$ :

note: the numbers in upright type in the table are actual values; those shown in italics are the expected values for each cell.

Table 4: The relationship between the Perceived Importance and Success in the treatment of Organisational Issues

\begin{tabular}{lccc}
\hline & $\begin{array}{l}\text { Successful in } \\
<30 \% \text { of } \\
\text { projects }\end{array}$ & $\begin{array}{l}\text { Successful in } \\
>30 \% \text { of } \\
\text { projects }\end{array}$ & \\
\hline $\begin{array}{l}\text { Organisational issues are the most important } \\
\begin{array}{l}\text { Organisational issues are more important than } \\
\text { technical issues }\end{array}\end{array}$ & $\mathbf{1 1 7}(120.2)$ & $\mathbf{5 0}(45.2)$ & 88 \\
$\begin{array}{l}\text { Organisational issues are equally important to } \\
\text { technical issues } \\
\text { Technical issues are more important than } \\
\text { organisational issues }\end{array}$ & $\mathbf{9 1}(92.9)$ & $\mathbf{1 0 0}(98.1)$ & 191 \\
& $\mathbf{2 7}(17.0)$ & $\mathbf{8}(18.0)$ & 35 \\
\hline
\end{tabular}

Significant at the $1.0 \%$ level; $\chi^{2}=12.67>11.34=\chi^{2}(0.010)$, 3df. 
Table 5 The Relationship between Approach and Success in treating Organisational Issues

\begin{tabular}{lccc}
\hline & $\begin{array}{l}\text { Successful in } \\
<30 \% \text { of } \\
\text { projects }\end{array}$ & $\begin{array}{l}\text { Successful in } \\
>30 \% \text { of } \\
\text { projects }\end{array}$ & \\
\hline During requirements analysis & $\mathbf{5 8}(63.5)$ & $\mathbf{7 3 ( 6 7 . 5 )}$ & 131 \\
During feasibility study & $\mathbf{3 7 ( 4 8 . 0 )}$ & $\mathbf{6 2}(51.0)$ & 99 \\
Explicitly throughout project & $\mathbf{2 7 ( 3 9 . 7 )}$ & $\mathbf{5 5}(42.3)$ & 82 \\
Independent impact analysis & $\mathbf{1 4}(16.0)$ & $\mathbf{1 9}(17.0)$ & 33 \\
Implicitly throughout project & $\mathbf{7 8 ( 7 6 . 0 )}$ & $\mathbf{7 9}(81.0)$ & 157 \\
Rarely considered & $\mathbf{6 5 ( 3 5 . 8 )}$ & $\mathbf{9 ( 3 8 . 2 )}$ & 74 \\
& 279 & 297 & 576 \\
\hline
\end{tabular}

Significant at the $0.1 \%$ level; $\chi^{2}=60.23>20.52=\chi^{2}(0.001)$, $5 \mathrm{df}$.

Table 6: The Relationship between Frequency of Treatment and Success in treatment of Organisational Issues

\begin{tabular}{lcccc}
\hline Organisational Issues Category & $\begin{array}{l}\text { Successful } \\
\text { in }<30 \% \text { of } \\
\text { projects }\end{array}$ & $\begin{array}{l}\text { Successful } \\
\text { in }>30 \% \text { of } \\
\text { projects }\end{array}$ & F ratio & Significance \\
& 2.61 & 2.25 & 35.57 & 0.00 \\
\hline 1 Organisational Contribution & 2.96 & 2.57 & 38.45 & 0.00 \\
$\mathbf{2}$ Human Issues & 2.73 & 2.28 & 28.79 & 0.00 \\
$\mathbf{3}$ Transitional Issues & 3.59 & 3.14 & 38.95 & 0.00 \\
\hline 4 Organisational Alignment & &
\end{tabular}

